\title{
Performance Based Analysis of a Historic High Rise Building
}

Open Access

\author{
Anindya Dutta*, Ronald Hamburger and Stephen T. Bono
}

Simpson Gumpertz \& Heger, Inc., The Landmark@ One Market Street, Suite 600, San Francisco, CA 95105, USA

\begin{abstract}
The authors employed high-fidelity computer modeling to analyze the probable seismic performance of an existing high-rise, steel frame building with unreinforced masonry infill walls in downtown San Francisco. The Pacific Telephone and Telegraph Co. building at 138 New Montgomery is a 26-story, historic office building. Constructed in 1926 this building was the tallest building in the western United States for a long period of time. The building's structural system comprises perimeter unreinforced brick masonry walls infilled within and supported by a steel frame. We conducted our analysis in support of the building's conversion to residential occupancy. As a result of the occupancy conversion, along with associated architectural modifications throughout the building, Section 3403 of the San Francisco Building Code (SFBC) requires a seismic upgrade such that the building has a code-compliant lateral-force resisting system with no less than $75 \%$ of the strength specified by the code for new buildings of similar occupancy and structural system. Since the existing building does not have a lateral force-resisting system recognized by current U.S. codes, compliance with the prescriptive requirements would have required expensive retrofits. Instead, the authors employed a performancebased approach using the existing masonry infilled steel frame for a substantive portion of the building's seismic resistance, together with a new supplemental interior reinforced concrete shear wall. Rather than design to achieve codespecified strength limits, we used nonlinear response history analysis to demonstrate acceptable behavior under Maximum Considered Earthquake (MCE) shaking. Detailed modeling of the interaction between the masonry infill and steel frame is a key component of this approach.
\end{abstract}

Keywords: Computer modeling, non-linear finite element analysis, performance based analysis, infilled brick masonry, seismic retrofit.

\section{INTRODUCTION}

For many years, the tallest structure in San Francisco, the 138 New Montgomery Building located at the corner of New Montgomery and Minna Streets has been designated by the City of San Francisco as a Class A landmark structure. The building has 26 above-grade stories, a basement and subbasement. It was constructed in 1926 as the headquarters for the Pacific Telephone and Telegraph Company and in fitting with this use the exterior façade features extensive terra cotta finishes and ornamentation. Construction consists of reinforced concrete floor and roof slabs supported by a complete vertical load carrying steel frame. Superstructure loads are supported on shallow reinforced concrete foundations. Perimeter frames are provided with heavy gusseted "wind connections" intended to permit the building to resist lateral (wind and earthquake) loads in a manner similar to modernday steel moment resisting frame construction. Perimeter walls are unreinforced brick masonry infill within and supported by the steel frame. An extensive upgrade of the perimeter walls was conducted in the late 1980s and early 1990 s and consisted of the replacement of damaged terra cotta tile veneers, improvement of the anchorage and attachment of these veneers to the brick masonry substrate,

*Address correspondence to this author at the Simpson Gumpertz \& Heger, Inc., The Landmark@ One Market Street, Suite 600, San Francisco, CA 95105, USA; Tel: 415-343 3057; Fax: 415-495 3550;

E-mail: ADutta@sgh.com replacement of masonry ornamentation with fiberglass replicas, bracing of parapets and bracing of interior hollow clay tile partitions within the historic lobby. Reinforced concrete masonry unit walls were introduced at the ends of one wing, as well.

The current owners purchased the building in the summer of 2007 with the intent to convert the structure to luxury residential condominiums. Since the required reconfiguration of most interior spaces, constitutes "Substantial Change" under Section 3403 of the San Francisco Building Code (SFBC) [1], the code requires seismic upgrade such that the building contains a code-conforming lateral force-resisting system having at least $75 \%$ of the strength required for new buildings of similar size and occupancy. As the SFBC does not recognize steel frames with unreinforced masonry brick infill as a lateral force resisting system compliance would require introduction of a new, compliant, lateral forceresisting system. Further, since the perimeter masonry walls are quite rigid, and also somewhat fragile the new system would require substantial stiffness, to demonstrate compatibility with the walls.

Preliminary analysis indicated this approach would require extensive, costly retrofits including introduction of shear walls at undesirable locations that would interfere with the historic building fabric as well as interfere with the architectural layout of units. In addition, for reasons of market viability, as well as avoidance of future liability from unit owners, the Owner expressed a need to obtain building per- 
formance similar to that advertised for recently constructed high rise condominium buildings in San Francisco conforming to modern building codes. Consequently, SGH implemented a performance based design approach based on the American Society of Civil Engineers' Seismic Rehabilitation of Existing Buildings (ASCE 41-06) [2]. A key aspect of this approach was our development of hysteretic models and acceptance criteria for the existing infill wall system. In addition to using these existing elements, which provide roughly $50 \%$ of the structure's final lateral resistance, we provided a backup reinforced concrete shear wall system that resulted in acceptable drifts and damage, demonstrating through the alternative means provisions of Section 104, equivalence to the requirements of the 2007 SFBC.

\section{EXISTING BUILDING}

The 138 New Montgomery St. building is L-shaped in plan with the long legs extending along New Montgomery and Minna Streets. The two orthogonal legs are approximately of the same length, $49 \mathrm{~m}(160 \mathrm{ft})$ and $45 \mathrm{~m}(147 \mathrm{ft})$ respectively. The short faces parallel to 3rd St. and Natoma St have lengths of $14 \mathrm{~m}(45 \mathrm{ft}$.) and $17 \mathrm{~m}(55 \mathrm{ft}$.) respectively. This footprint continues till the 23rd floor at which level the building sets back by about $3 \mathrm{~m}(9 \mathrm{ft})$ along the New Montgomery and Minna Street faces. The roof is located $112 \mathrm{~m}$ (369 ft) above the ground level. Above the roof, the elevator core rises another $13 \mathrm{~m}(44 \mathrm{ft})$ and forms a tower.

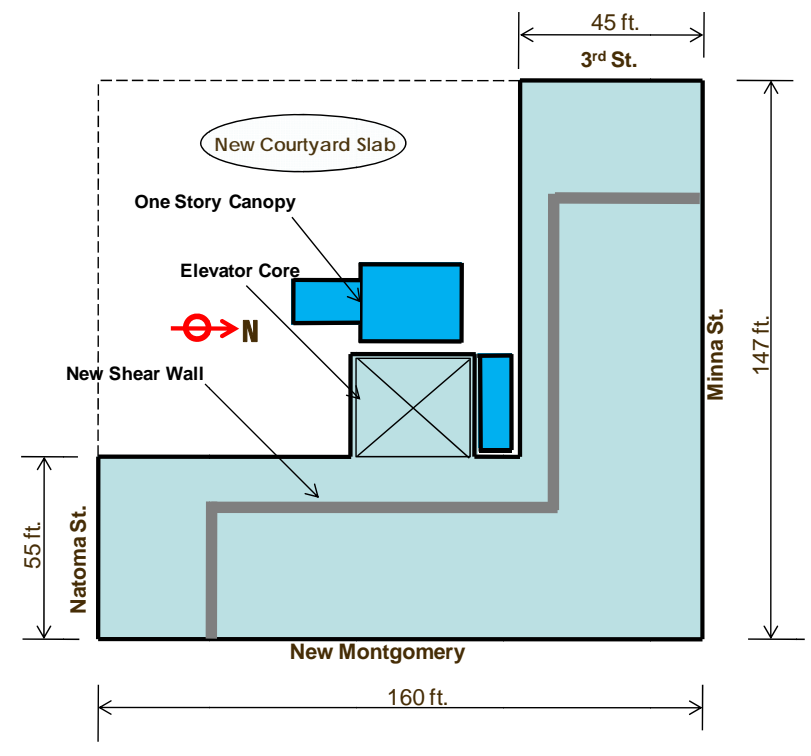

Fig. (1). Building plan view.

Floors are one-way reinforced concrete slabs of approximately $100 \mathrm{~mm}$ (4 in.) thickness with a $33 \mathrm{~mm}(1-1 / 2 \mathrm{in}$.) concrete topping. Floor slabs span to reinforced concrete joists which in turn are supported by steel framing located along column lines. Steel frames located at the building perimeter are provided with heavy gusseted "wind connections," which were intended to permit the building to resist lateral (wind and earthquake) loads in a manner similar to modern-day steel moment resisting frame construction. Perimeter walls are unreinforced brick masonry infilled within and supported by the steel frame. Foundations are reinforced concrete and are of two types: individual or combined foot- ing. (Fig. 1) shows a schematic plan of the overall structure and (Fig. 2) is a photographic elevation of the building as seen from the southwest.

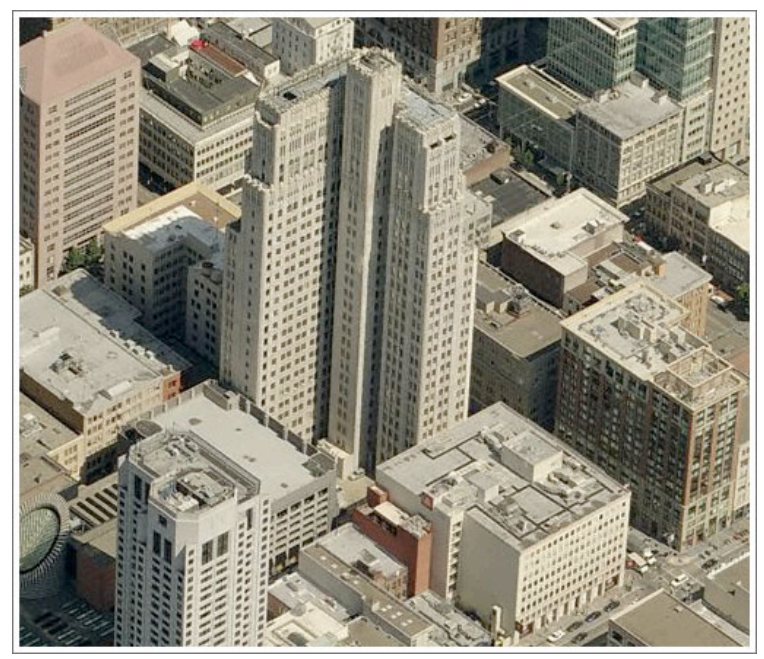

Fig (2). Aerial view.

\section{DESIGN PROCESS}

The City of San Francisco permits performance-based designs under the alternative means and methods provisions of the SFBC, but subject to approval by independent peer review. The City-appointed peer review panel typically includes a practicing structural engineer, as chair, a structural engineering researcher, and a ground motion expert. This panel examines and approves the criteria, overlooks the design calculations and ensures that the final design follows the intent of the agreed criteria. Upon successful completion, the peer review must certify to the City that they have performed the review and that in their opinion, the design is capable of performing in an equivalent or better manner than comparable structures designed to conform to the building code's prescriptive provisions.

For many years the SEAOC Blue Book has described the performance anticipated of new code-conforming structures. More recently the Blue Book goals have been supplanted by commentary to the NEHRP Provisions (BSSC, 2003) [3]. For buildings of ordinary occupancy, this performance is stated as a goal to provide an acceptably small risk of collapse given that the structure experiences Maximum Considered Earthquake (MCE) shaking. More recently, the Building Seismic Safety Council has clarified that not greater than a $10 \%$ conditional probability of collapse, given MCE shaking is the goal. This goal has also been adopted by the FEMA P-695 (ATC, 2009) [4] methodology for development of structural system response modification coefficients and other seismic performance factors for building codes. These criteria provide an "equivalency goal" for new construction, but do not address criteria for existing buildings. The SFBC and other codes have traditionally accepted design strengths for existing buildings that are $75 \%$ of those required of new buildings, but it is not clear how this translates to performance.

We initially proposed to demonstrate acceptable collapse resistance capability for Design Earthquake (DBE) shaking, 
rather than MCE, in keeping with the $75 \%$ reduction embodied in the SFBC. However, early in the review phase the peer review team indicated the building should be analyzed for MCE shaking, as opposed to a reduced level. MCE shaking was defined as ASCE-41's Basic Safety Earthquake 2 (BSE2 ). BSE- 2 hazard is defined as $2 \%$ probability of exceedance in 50 years and deterministic cap estimate of ground motion based on $150 \%$ of median attenuation likely to be experienced at a site. Fortunately, the peer review team agreed that deformation-controlled actions including coupling beam rotations and in-plane flexure of new shear walls could be assessed against the ASCE-41 Collapse Prevention (CP) performance criteria for BSE-2 shaking considering $75 \%$ of the mean demands from our suite of analyses. Other potentially brittle actions, or actions associated with failures that are clear risks to life safety, including drifts in infill wall panels, compression and tension in existing steel columns, beam-column connection capacities were to be evaluated for the full BSE-2 demand from MCE analysis. Further, the peer reviewers also required computation of demand by aligning the pairs of ground motions such that maximum response of the entire suite of 7 records was produced along one principal direction of building response, and that then the suite be rotated $90^{\circ}$ to capture maximum response in the orthogonal axis. (Fig. 3) illustrates these directions of ground motion application.

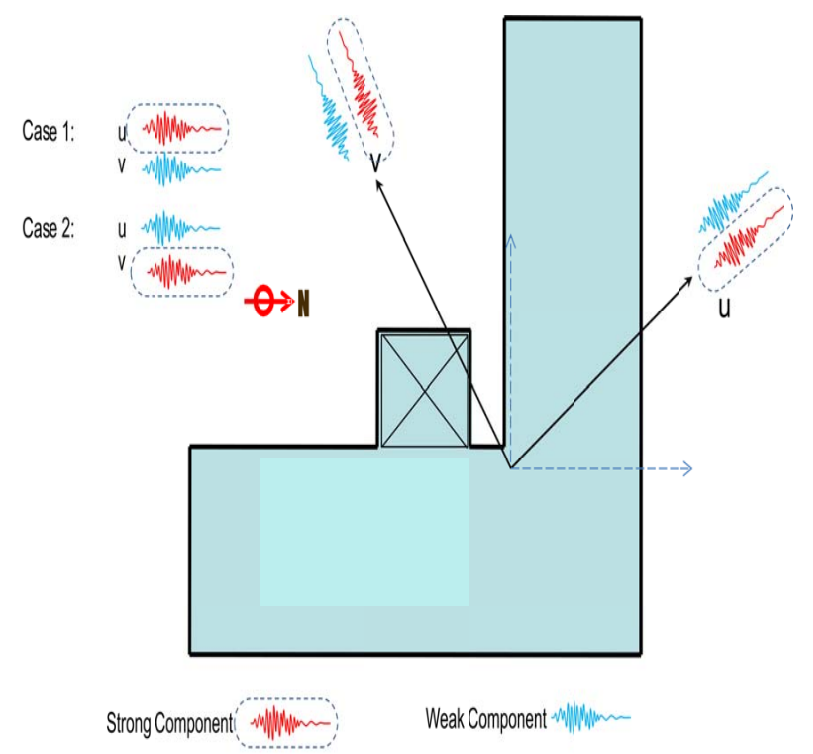

Fig. (3). Strong and weak component orientation for time history analysis

As part of the seismic evaluation, SGH identified the building's critical failure modes and to ensure adequate protection against onset of these failures. These modes included:

Excessive Cracking and Spalling of the Terracotta Façade and Brick Masonry Due to Large Interstory Shear Deformations

This could produce falling debris which would be potentially hazardous to persons at street level, near the building. The new shear wall provided the building with sufficient stiffness and strength to limit the mean shear deformation of the exterior walls during BSE-2 shaking to levels below which spalling is expected to occur.

Failure of tension splices in exterior columns due to forces imposed on the columns as a result of frame action and by interaction with the infill and new walls: Since the existing splices are weaker than the columns themselves, large column uplift forces can result in splice failure resulting in the opening of vertical gaps in the columns as the upper and lower tiers separate. If the uplift at these gaps is significant, there is potential that upon reverse seismic loading, as the column force transitions from uplift to compression, the column may not reseat itself properly atop the lower portion, resulting in a local collapse. Further, large displacements at column splices could cause unacceptable damage to the exterior wall, as described above. Where our analyses showed such splice failures can occur under BSE-2 shaking, we either strengthened these splices or provided an adjacent column (in the form of a concrete pilaster with heavy reinforcing) to act as a tensile tie across the splice and limit vertical gap displacement.

\section{Buckling Failure of Perimeter Columns Under Compres- sion}

The same frame action and interaction with the infill wall discussed above can cause excessive compressive loads in the columns resulting in buckling. We identified any columns that had insufficient compression capacity to resist mean MCE shaking demands and provided reinforcing (in the form of flange plates etc.) to bolster their compressive capacity.

\section{Failure of the 23rd Floor Transfer Girder to Column Connection}

A setback in the building exterior wall line occurs at the 23rd floor. A series of transfer girders are provided at this level to support the wall and floors above. If seismic overturning loads in the wall above are excessive, there is potential for flexural yielding of the transfer girders or failure of the connections of these girders to the supporting columns. If either occurs, partial collapse of the upper portion of the building could occur. We monitored the loads imposed on these girders and their connections at BSE-2 shaking and designed appropriate retrofits.

\section{Failure of Beam to Column Connections Within the Infill}

The interaction of the masonry infill and perimeter steel frames induces axial forces, shears and bending in the frame elements. If these forces exceed the capacity of the beam-tocolumn connections, the beams could shear off the columns, resulting in local collapse and possibly wide spread failure as the perimeter frame degrades in strength. We addressed this issue by limiting the global drifts under MCE shaking to a level that will not impose excessive forces on these connections. The connection capacities and forces imposed on them by the infill masonry were evaluated using a combination of analytical models and hand calculations. Where demands were found to exceed capacity, we provided strengthening.

\section{Shear and Flexural Overstress of the Floor Diaphragms:}

The concrete floor slabs act as diaphragms to transfer inertial forces to and between the existing perimeter and new 
interior walls. If shear and flexural forces on these diaphragms become excessive, the diaphragms can lose their ability to effectively tie these elements together and there is potential that walls facing 3rd Street and Natoma could become unstable. We checked the diaphragms to assure adequate strength under MCE shaking and provided strengthening where necessary.

\section{Excessive Foundation Settlement}

The shallow reinforced concrete foundations transfer both gravity and overturning forces from the masonry infilled perimeter steel frames and new concrete shear wall into the soil. If moments and shears induced by overturning forces exceed the flexure and shear strength of the foundation, localized bearing pressures could exceed soil ultimate bearing capacity resulting in excessive settlement. We checked bearing pressures and displacements of the foundation with a grillage foundation model using a MCE equivalent pushover loads. Pushover loads were based on expected roof displacements.

Our analyses and design were specifically performed to provide assurance that none of these critical behavioral modes is likely to occur at loading within the analysis regime stipulated by the review team.

\section{EVALUATION OF UNREINFORCED MASONRY IN- FILLED FRAMES}

Infill unreinforced masonry walls are commonly analyzed using an equivalent compression strut (see ASCE 4106, Section 7.4.2). However, the recommendations in ASCE 41-06 were developed mainly for solid infills and have acceptance criteria only for Life Safety and Collapse Prevention performance levels. Although ASCE 41-06 has some recommendations for modeling infills with openings, the complexity of the framing geometry (deep gusseted connection) in the $138 \mathrm{New}$ Montgomery building warranted a more detailed evaluation approach. In addition, since one of the major design goals was to mitigate damage to exterior terracotta, we decided to use an alternative approach to model the load deformation behavior of the infilled masonry.

We used ABAQUS [5] software to develop nonlinear finite element models of typical exterior wall infill panels. Each panel model includes a representation of a single story and single bay of steel framing, concrete and masonry infills. (Fig. 4) illustrates one such panel in the perimeter wall of the New Montgomery elevation. Panel models generally include two columns, each of which runs two stories tall, extending from the mid-height of a story below, through a complete story and to the mid-height of a story above; mullion elements, located between columns, and the spandrels extending from mid-bay of the panel on either side of that being modeled. We set boundary conditions to allow lateral translation of the top of the panel relative to the bottom, while maintaining stress transfer conditions similar to that which would occur in the actual building. We constructed a series of these panel models to capture the most common panel geometries.

Our monotonic analysis of the panel models provided information on their nonlinear force-displacement behavior and the likely extent of damage at different levels of story drift. (Fig. 5) shows the building's exterior wall elevation along Minna St. and identifies the panels modeled in ABAQUS.

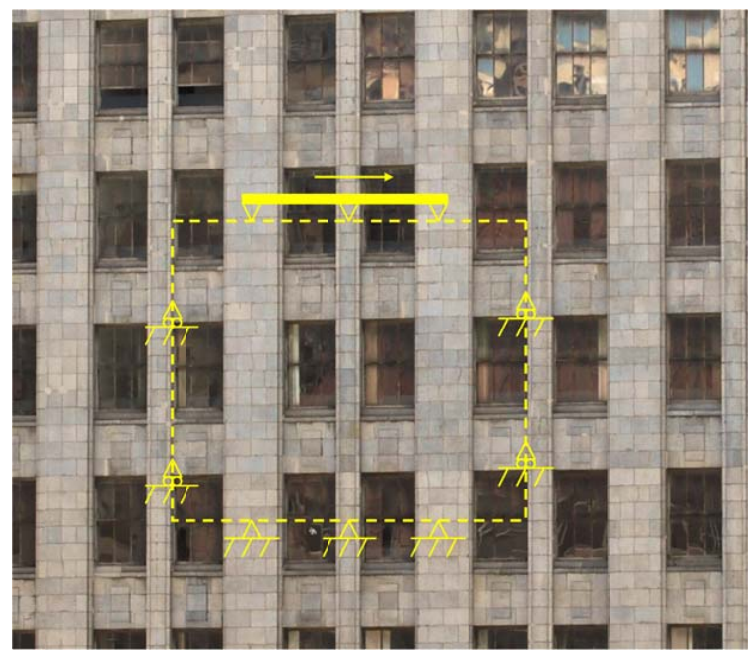

Fig. (4). Portion of wall included in panel model.

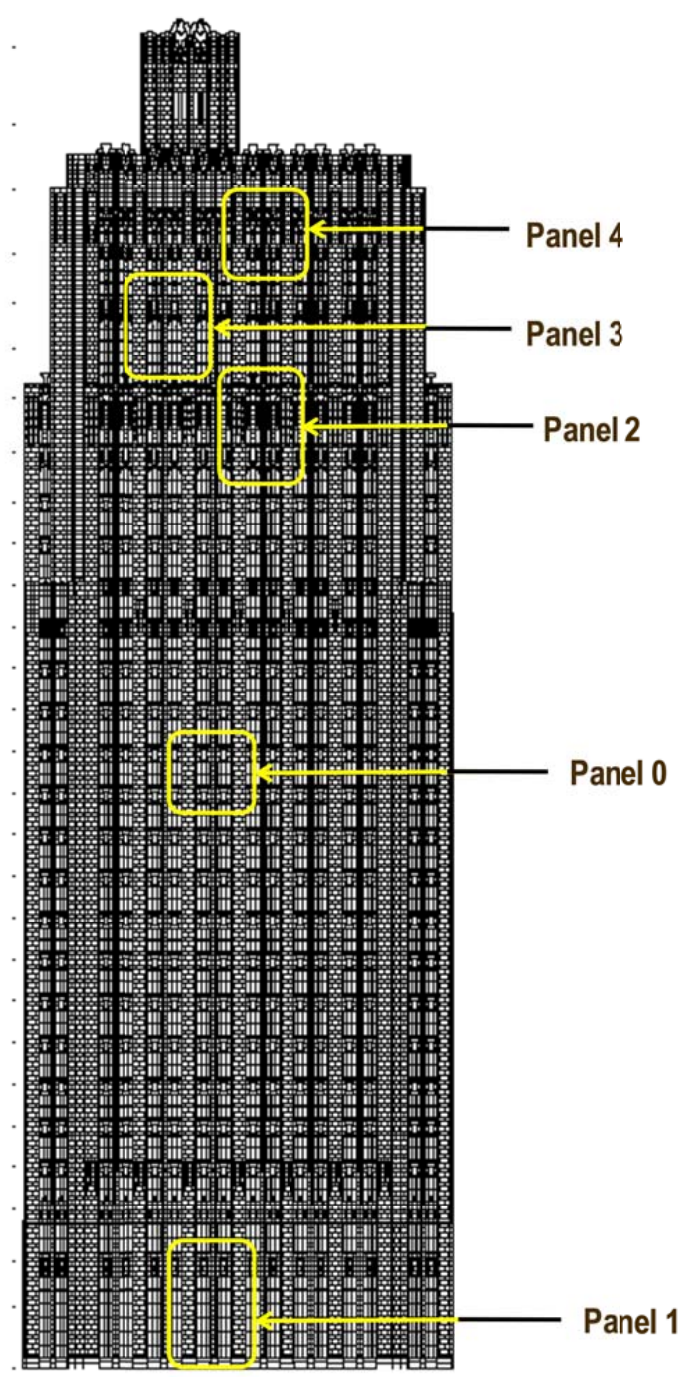

Fig. (5). Minna Street Elevation showing the modeled panels in ABAQUS. 
We also developed a global structural model using CSI Perform [6] software. This three dimensional mathematical model of the entire building captures its geometry, mass distribution, and nonlinear force-deformation behavior, considering the interaction of the masonry, concrete and steel elements, as well as the behavior of critically loaded diaphragms and the flexibility of the foundations resulting from deformation of the underlying soils.

In essence, we used the panel models to develop forcedeformation relationships of individual exterior wall panels that we then used to construct the global model. We used the global model to perform nonlinear dynamic analysis of the building's response to earthquake shaking. The primary parameters we obtain from the global analyses are the shear drift deformation demands on the perimeter infill wall and frame elements, critical diaphragm demands, and overturning demands on columns and foundations. We then used the information obtained from the global model on peak shear deformation demand of the perimeter walls to predict damage states and acceptability of response of the masonry infill panels, based on the information obtained from the panel models.

\section{PANEL MODEL}

Each panel model includes representation of the structural steel, concrete and masonry using small, nonlinear finite elements in layers. (Fig. 6) shows an elevation of one representative panel model, indicating all layers. (Fig. 7) shows each of the three layers contained in the model including the steel, concrete, and masonry.

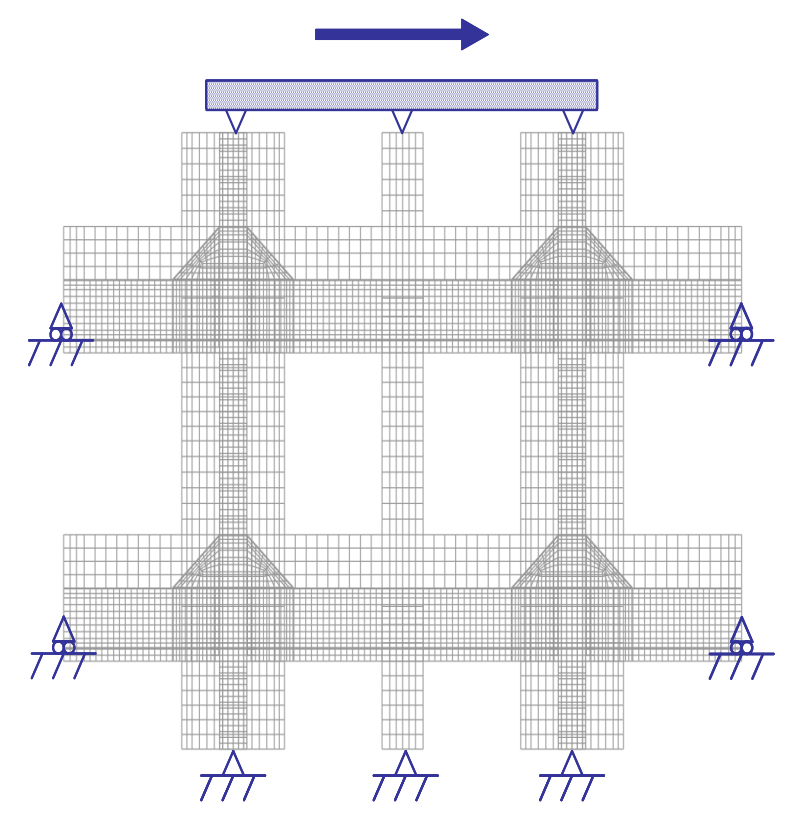

Fig. (6). Meshing and elements of representative panel model.

The connectivity between the element layers reflects the expected behavior of the materials in the structure. Neither concrete nor masonry can apply tension to the steel, but both can bear against the steel in compression. The concrete can transfer shear stress to the steel, representing the bond that naturally occurs when concrete is cast against steel. The masonry can slip with transmission of nominal shear through friction, relative to both the concrete and steel, representing the poor bond qualities of masonry mortar to both steel and concrete.

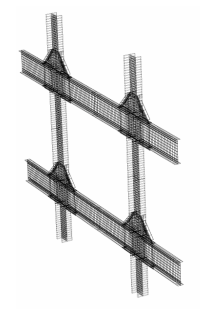

Steel frame

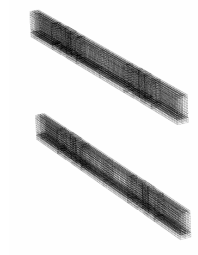

Concrete encasement

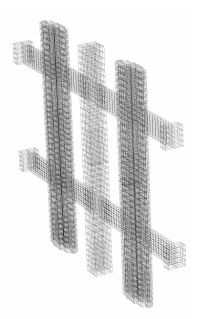

Masonry walls
Fig. (7). Isometric view of three material layers used in panel model.

A key item in proper modeling of the interaction between the masonry, concrete and steel component is the choice of the correct constitutive relationship of the various components. For the infill masonry we used the average values for the elastic modulus and ultimate compressive stress obtained from flat jack tests that were conducted as part of the material strength investigation. These values are $5 \mathrm{MPa}$ (725 psi) and $11 \mathrm{MPa}$ (1610 psi), respectively. To describe the nonlinear compression response we used the above values in the modified tri-linear relationship suggested by Kaushik et al... (2007) [7] and plotted in (Fig. 8). We also calculated the tensile strength for the clay brick masonry material using the relation suggested by Drysdale et al.... (1982) [8]. We assumed that the infill masonry after reaching the tensile strength linearly loses its tensile capacity at a total strain value 11 times the peak tensile strain, in an approach similar to that suggested by Zarghamee (1990) [9].

$f_{t}=0.2 \sqrt{f_{m}^{\prime}(M P a)}$

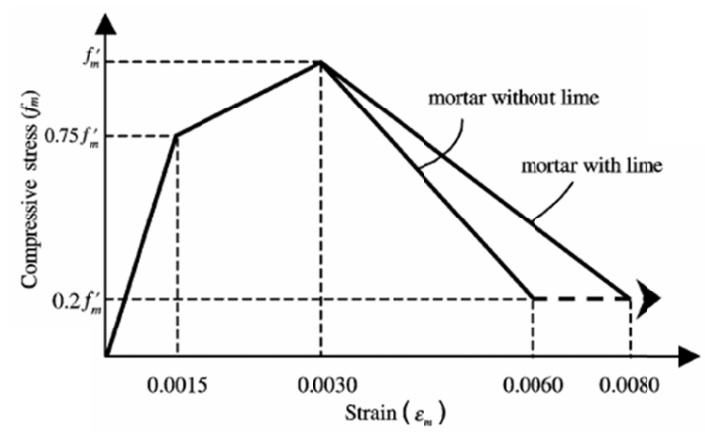

Fig. (8). Masonry stress strain relation in compression by Kaushik et al... (2007).

In a somewhat arbitrary fashion, we designated this strain as corresponding to the onset of "visible cracking." We later confirmed this assumption during our benchmark analysis of a laboratory test frame where we produced good agreement with the observed damage patterns. (Fig. 10) shows the complete stress-strain response for the masonry infill used in our panel models.

To develop the stress strain relationship for concrete we used the mean compression test value of $26 \mathrm{MPa}$ (3790 
psi). We calculated the elastic modulus using the standard ACI 318-08 [10] relationship that yielded a value of $24 \mathrm{MPa}$ $(3509 \mathrm{ksi})$. For the tensile strength of concrete we adopted a value of $2.5 \mathrm{MPa}$ (369 psi) based on the lower bound value described in Section 18.3.3 in ACI 318-08.

$E_{c}=4700 \sqrt{f_{c}^{\prime}(M P a)}$

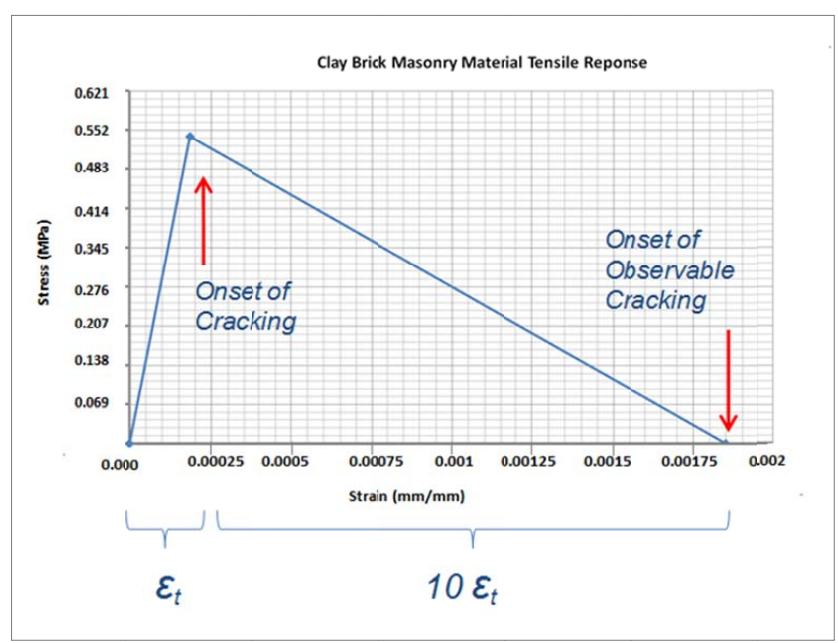

Fig. (9). Masonry stress strain relation in tension.

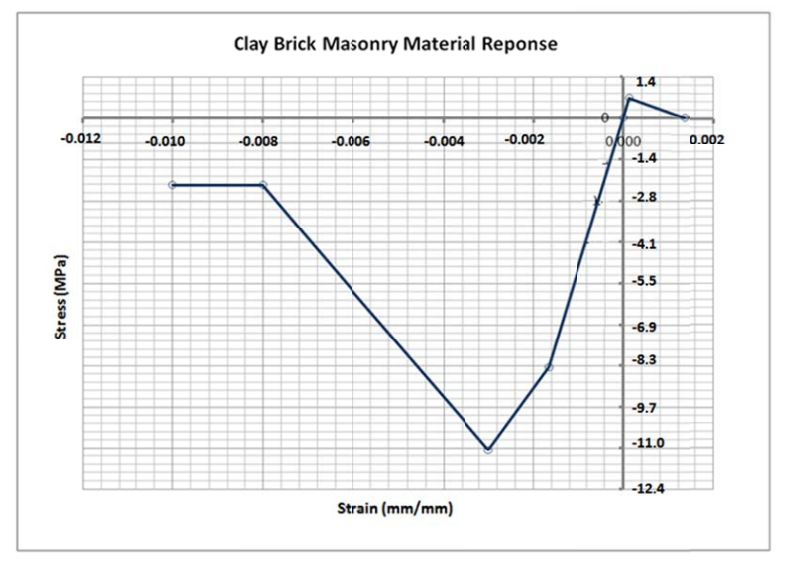

Fig. (10). Adopted stress strain relation for infill masonry.

With these values we generated the complete nonlinear compression response using the Saenz relationship as reported by Elwi et al... (1979) [11]. We modeled the tensile behavior of concrete per Bazant et al.... (1984) [12]. Using the equations suggested in that paper the tensile strength of concrete linearly reduces to zero at 6 times the peak tensile strain. (Fig. 11) shows the composite concrete material response used in the panel models.

Using an explicit solution technique, we subjected the panel models to a slowly increased lateral shear displacement profile in order to develop a representation of the panel's lateral stiffness at various levels of story drift. In order to understand the contribution of each of the materials, we performed separate analyses for the bare steel frame, for the case of the steel frame together with the concrete and for the case of all three materials being present. (Fig. 12) presents the resulting pushover curves for the bare steel frame and for the model containing all three materials for a typical panel. In this figure, the horizontal axis represents shear drift ratio which is the lateral story displacement, exclusive of displacements resulting from axial deformations of columns below the panel, divided by the story height. A value of $0.5 \%$ for a $4 \mathrm{~m}$ (13-foot) story represents a lateral shear deformation of the top floor relative to the floor below of approximately $19 \mathrm{~mm}(3 / 4 \mathrm{inch})$. The vertical axis indicates that shear force resisted by the composite structure, in thousands of pounds. The stiffening and strengthening effects of the masonry and concrete materials is evident increasing the capacity and stiffness approximately $25 \%$ and $30 \%$ respectively above the bare steel frame.

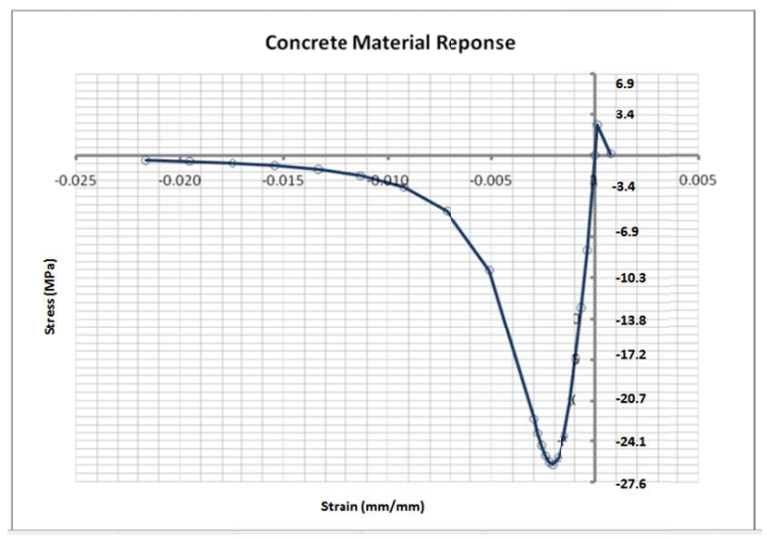

Fig. (11). Adopted stress strain relation for concrete.

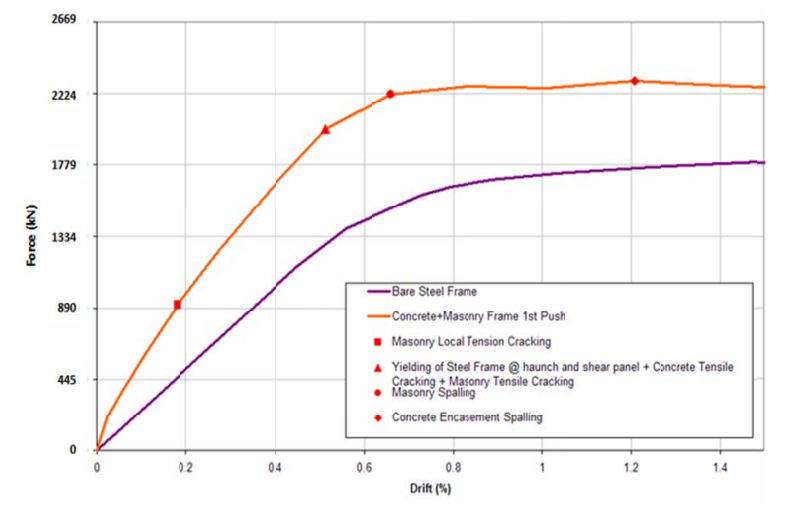

Fig. (12). Panel pushover curves for bare steel and composite model.

The figure also shows judgmentally selected points along the response curve which correspond to damage events that will initiate as the building responds to ground shaking. The symbol indicates the initiation of tensile cracking in the masonry. The $\Delta$ indicates initiation of yielding in the steel frame, the $\bullet$ initiation of crushing and spalling of the masonry and the initiation of crushing and spalling of the concrete. From this analysis, we developed a series of "snapshots" of the probable damage to the masonry walls at various lateral story drift ratios. (Fig. 13) is representative and indicates expected masonry infill cracking and steel framing stress contours at $1 \%$ shear drift demand. In this plot, the red patches indicate elements where the computed principal tensile strain exceeds 11 times the cracking strain. We define 
this limit as the onset of observable cracking as shown in Fig. (9). The blue patches indicate elements where the strains are over the cracking strain but less than that at the onset of visible cracks as defined in the same figure.

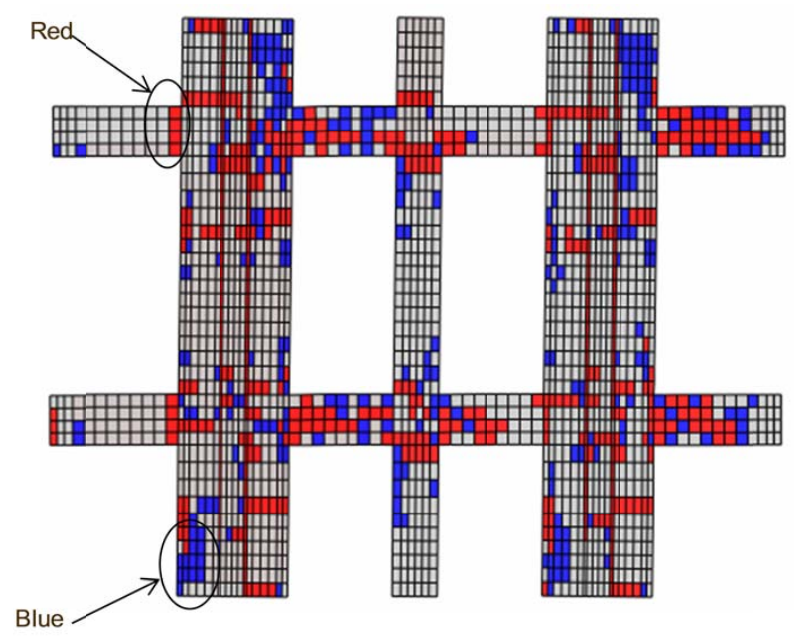

(a) Masonry cracking pattern at $1 \% \mathrm{drift}$

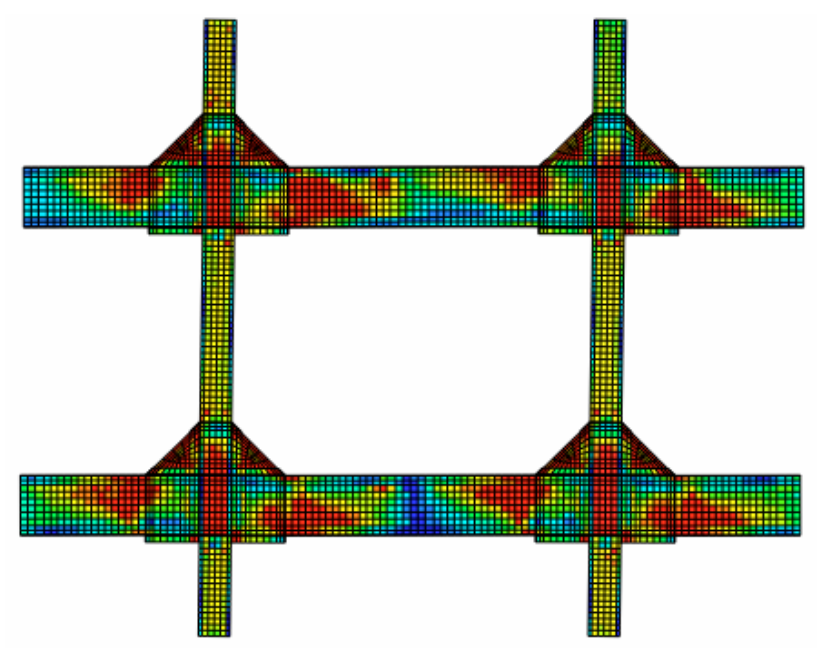

(b) Steel frame yielding pattern at $1 \% \mathrm{drift}$

Fig. (13). Masonry cracking and steel yielding pattern at 1\% story drift.

It is worth noting that at drift levels expected in the retrofitted structure under MCE shaking $(\sim 1 \%)$, the haunched gusset in the typical panel is expected to yield in compression. We performed simple hand calculations using conservative effective length factors and convinced ourselves that the buckling capacity is almost identical to the haunch yield capacity in compression at these drift levels. However, since the masonry around the gusset is intact with minimal cracking at that level shows on Fig. (13a), we believe it will effectively confine the gusset forcing it to yield in compression rather than displacing horizontally and buckling out of plane.

We followed a similar approach for the other panels and on the basis of this collection of data, we infer that through in-plane shear drifts of approximately $0.2 \%$, typical masonry panels in the building will remain undamaged. Note that we conclude based on observance of damage patterns from past earthquakes that out-of-plane story drifts do not have significant effect on buildings of this type and therefore, future discussion of drift in this paper refers to drift within the plane of a particular wall. Some variation in damage state with drift occurs from panel to panel. In particular, where panels are relatively solid, with few openings, damage initiates at lower levels of drift. However, since there are relatively few such panels in the building, the overall effect of such damage on building performance is not particularly significant and in any event, is accounted for in our global modeling and analysis.

At story shear deformations of approximately $0.2 \%$ tensile cracking will initiate in the bed joints of the masonry, and the corresponding bed joints in the terra cotta tile, at the tops and bottoms of piers and mullions and where the spandrels frame into the sides of the piers. Minor cracking may also occur in the exterior masonry within the panel zone formed by the continuation of the piers through the spandrel pier intersection. At this drift level, this cracking would largely be unnoticeable following the earthquake and in most cases no repair would be required, though some increased susceptibility to moisture infiltration may exist.

At shear drifts of $0.3 \%$, some minor crushing of weaker mortars at the joint between the horizontal spandrels and vertical piers may occur. This may require repointing in a few cases to minimize water penetration. Tensile cracks in masonry will continue to extend and grow but should not require repair.

At shear drifts of $0.5 \%$ we anticipate that tensile cracking in the masonry will extend diagonally across the spandrel elements. Localized crushing may occur at the corners of the spandrels, requiring repair or replacement of some terra cotta units. Cracking of the concrete fill in the beams will have occurred, but this will not be evident nor will it be practical or necessary to repair.

At shear drifts approximating $0.8 \%$, the steel framing will experience extensive yielding accompanied by diagonal cracking and spalling within the spandrels as well as at the corners of the masonry piers and mullions. Extensive cracking will occur to the concrete fill in the spandrel beams. Expected repairs consist of localized removal and replacement of terra cotta in zones of local spalling and crushing, repointing and injection of cracks in masonry and concrete.

At shear drifts of $1 \%$ full plastic hinging of the steel frame initiates accompanied by major damage to the concrete and masonry elements in the spandrels and masonry elements in the piers. Removal and replacement of masonry units will be required at the bases and tops of piers and mullions and within the body of spandrels. Epoxy injection of concrete fill on beams will be required.

At shear drifts of $1.5 \%$ substantial damage to the framing and walls is expected along with some potential for shedding of pieces of masonry onto the street below. Repair actions may include requirements to substantially rebuild the masonry encasement of the framing. Significant permanent residual drift may occur that will require extensive work to bring the building back to plumb. We developed similar 


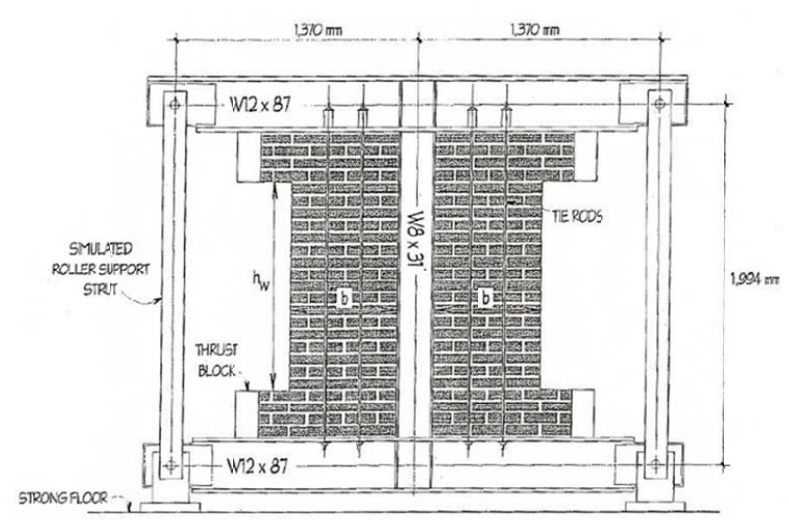

(a) Specimen tested by Schneider et al.

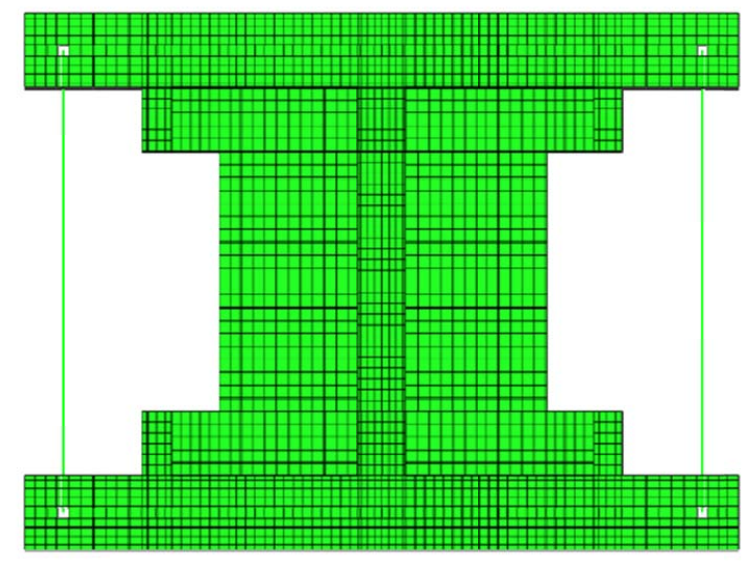

(b) ABAQUS model of test specimen

Fig. (14). Test specimen and ABAQUS model.

damage projections for each of the individual panel models that we studied for the entire building.

\section{VALIDATION OF ABAQUS MODELING WITH LABORATORY TESTING}

To confirm that our panel models are capable of suitably representing the behavior of real masonry infill panels, we constructed a panel model to replicate a laboratory test of a masonry infll frame (Schneider, et. al. 1996, 1998 [13, 14]). (Fig. 14a) illustrates the specimen tested by Schneider et al.... while (Fig. 14b) shows the ABAQUS model we used to represent this test specimen.

We used the same modeling techniques described above including the stress strain curves for masonry and concrete adjusted for the strengths in the test specimen. This was particularly important to confirm that our assumptions regarding cracking and spalling of masonry in the actual building models are consistent with that observed in Schneider's test.

(Fig. 15) extracted from the Schneider report illustrates the hysteretic data obtained for this infill specimen when subjected to increased cyclic testing. (Fig. 16) shows the backbone curves obtained from this test data and the monotonic backbone curve obtained from our ABAQUS model. We conclude that our ABAQUS panel models accurately represent the force-deformation behavior of infill panels through drifts of $0.2 \%$. At larger drifts, up through $1.4 \%$, our ABAQUS model is slightly conservative in that it moderately underestimates the strength of the masonry infill as compared with that obtained from the cyclic testing.

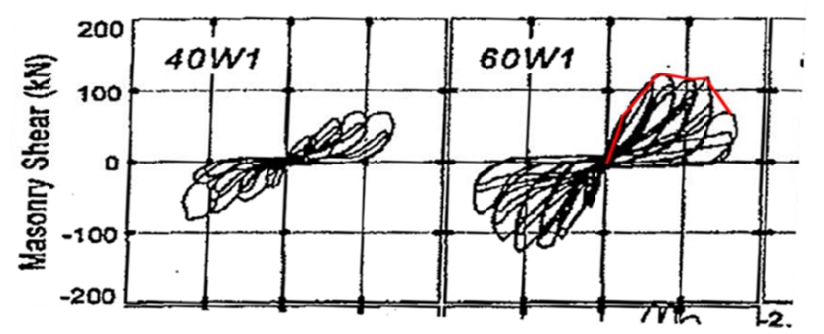

Fig. (15). Force deformation behavior of specimen tested by Schneider et al.

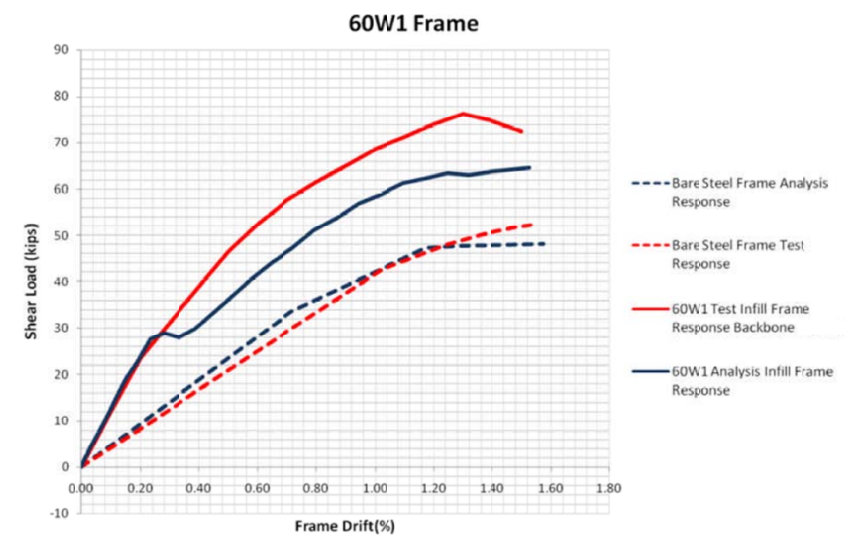

Fig. (16). Comparison of backbone curves obtained from test and benchmark analysis.

We also compared the damage patterns from the actual specimen to that predicted by the ABAQUS model. (Fig. 17) shows a comparison of the damage patterns of the tested specimen with the predictions from ABAQUS at $0.75 \%$ drift. In that ABAQUS plot, the red patches indicate the elements where the principal tensile strain in the elements have exceeded 11 times the cracking strain. We define this limit as the onset of observable cracking as shown in (Fig. 9). The blue patches indicate the elements with predicted strains in excess of the cracking strain but less than that at the onset of visible cracks. It should be noted that the damage patterns in the test specimen are from cyclic loading, while the damage plot from the ABAQUS model is from monotonic loading which explains the one-sided and generally under predicated nature of damage in the ABAQUS analysis. (Fig. 18) presents a similar comparison showing the damage patterns at $1.5 \%$ drift. The actual tested specimen clearly shows spalling at the bottom right corner at this drift level. The ABAQUS model also shows a rather enlarged red patch at the same location confirming the onset of spalling. We used this observation to define the limit state of spalling for the actual panels in the building. We infer that the onset of spalling can be reasonably predicted from the ABAQUS plots when there are a significant number of interconnected elements with signs of visible cracking. Physically this means that the tensile bond that holds the masonry pieces together is lost making the pieces prone to disintegration. 


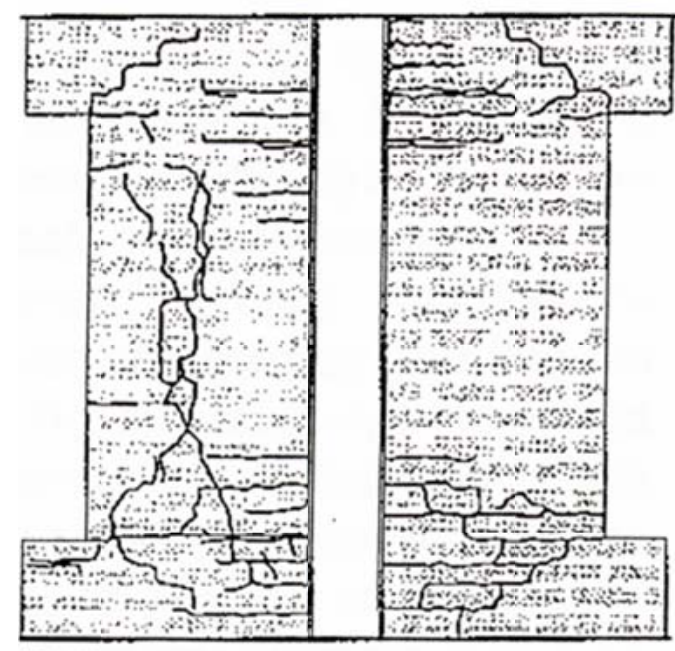

After $0.75 \%$ Drift
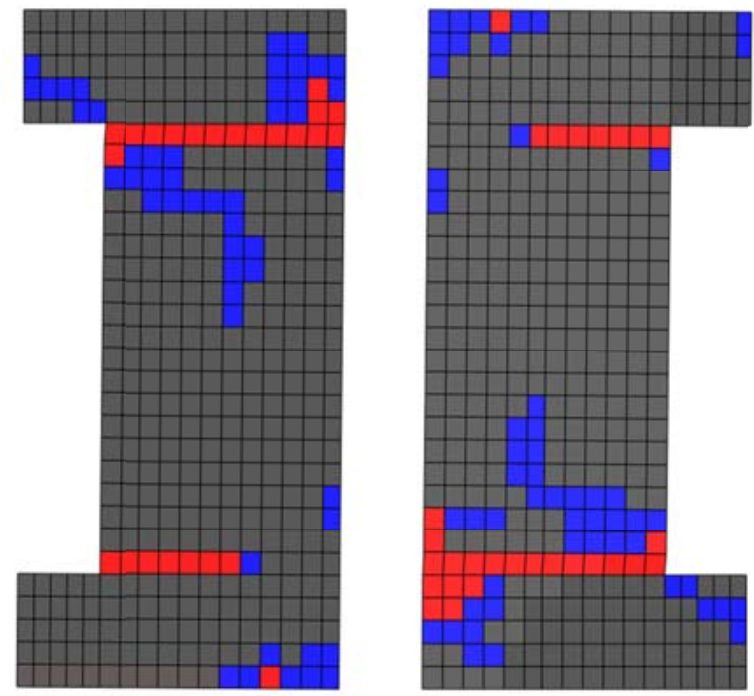

Fig. (17). Comparison of damage patterns in the tested specimen with ABAQUS predictions at $0.75 \%$ drift.
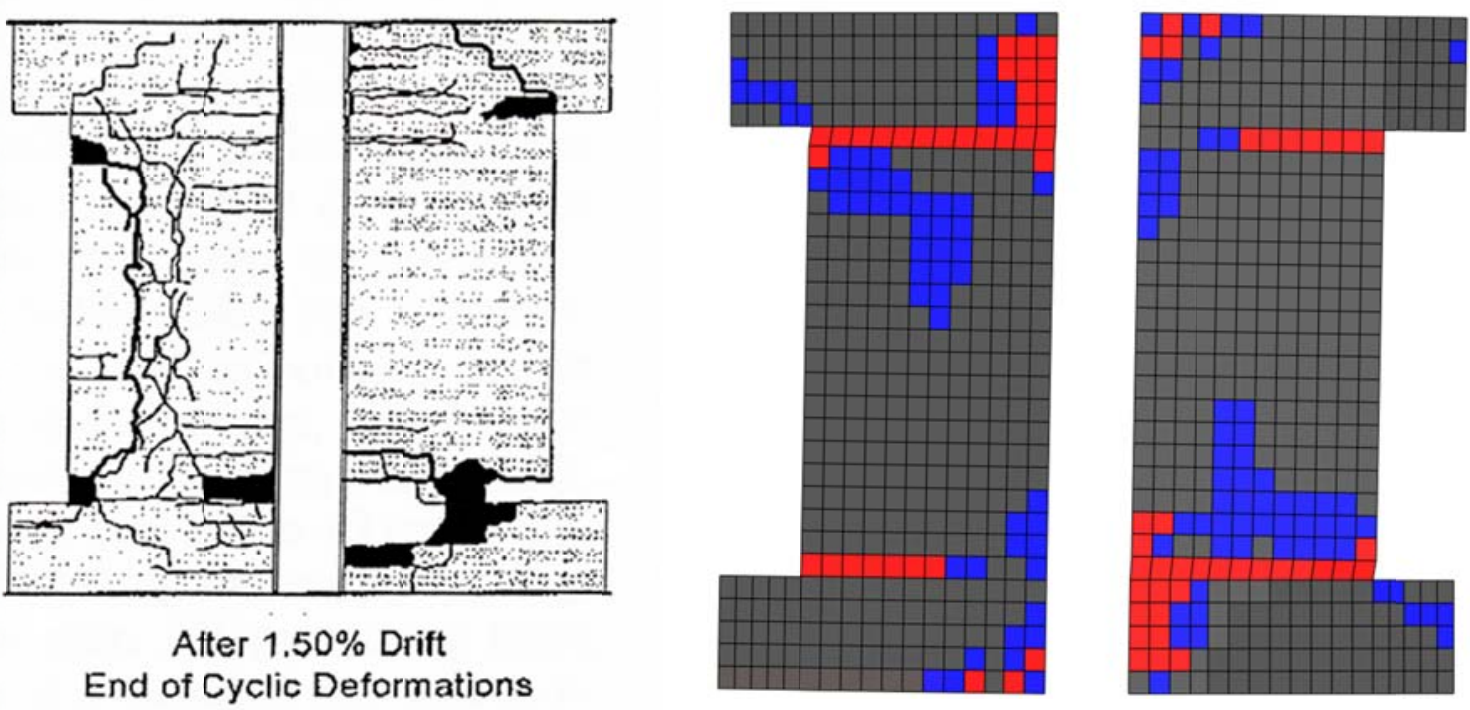

Fig. (18). Comparison of damage patterns in the tested specimen with ABAQUS predictions at $1.5 \%$ drift.

By comparing the pattern of blue and red spreads in the ABAQUS model and actual damage observed in Schneider's test, we were able to confirm our damage predictors for the panels. Hence, the benchmark analysis was the most important link between the finite element analysis and actual observed damage in the real specimen.

\section{GLOBAL 3D FINITE ELEMENT MODEL}

In order to predict the building's global response to MCE shaking we constructed a 3-dimensional, nonlinear analytical model of the entire building using CSI-Perform software. The model represents the entire structure, from the subbasement to the high roof, including the foundations. We modeled the beams and columns with non-linear fiber elements. Locally stiffened elements are used at the beam column joints to represent the stiffening effect of the large triangular gusset plates, where these occur. We modeled the diaphragms as rigid in the horizontal plane at all levels except at the ground level and below where we used flexible shell elements with reduced stiffness to account for cracking. We considered the column bases as fixed against horizontal translation at the foundation level. Since there is no formal hold-down of the columns to the foundation we released translation of the columns in the upward vertical direction. We provided a series of non-linear compression-only springs beneath the columns and new shear wall nodes to represent the compliance of the building's foundations. The geotechnical engineer of record suggested calculation of spring stiffness for subsoils using a subgrade modulus of $14.1 \mathrm{MN} / \mathrm{m}^{3}$ (90 kcf) up to a footing pressure of $0.5 \mathrm{MPa}(10 \mathrm{ksf})$ linearly decreasing to $6.3 \mathrm{MN} / \mathrm{m}^{3}$ (40 $\mathrm{kcf}$ ) at a bearing pressure of 1 $\mathrm{MPa}(20 \mathrm{ksf})$. At bearing deformations in excess of those producing $1 \mathrm{MPa}(20 \mathrm{ksf})$ pressure, the geotechnical engineer suggested that we consider the soil to have yielded, resulting in an essentially flat spring rate. Thus, we developed 


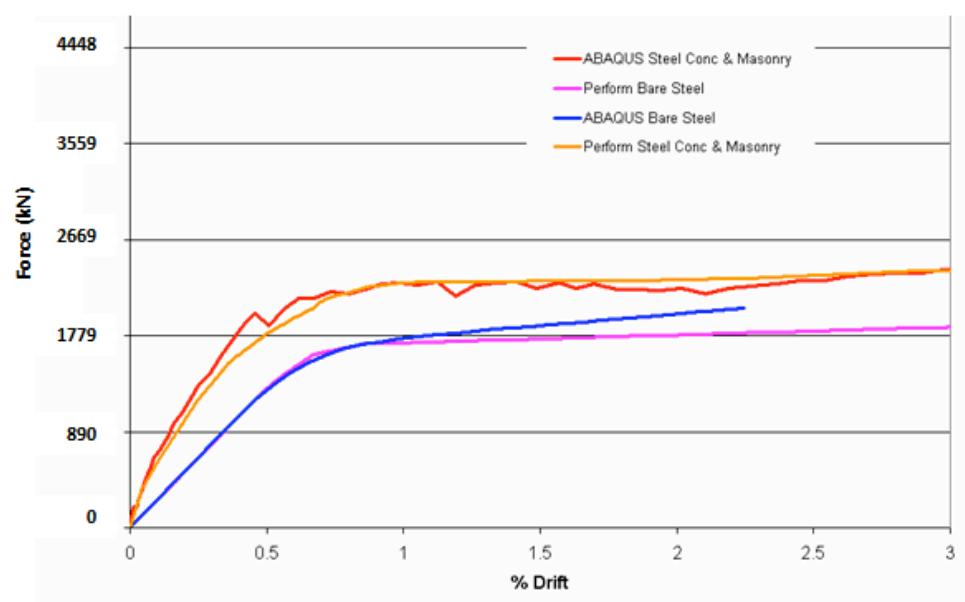

Fig. (19). Comparison of pushover curves obtained from global and panel models.

springs with a trilinear backbone formulation incorporating these three regimes of behavior. We performed a bounding analysis by considering $150 \%$ of these nominal stiffness in the first case and then $67 \%$ of the nominal values in the second case in accordance with ASCE 41.

To model the effects of the masonry infills we used a series of quadrilateral panel elements with one panel element placed in each bay in which infill framing exists. The nonlinear properties of the panel elements closely match the stiffening effects of masonry and concrete indicated by the panel models described in the previous section. To verify this, we first performed a pushover analysis of the building model using only the bare steel frame and checked the forcedeformation behavior of typical bays modeled as panels against the behaviors obtained for the bare steel frame in the panel models. The models produced results in close agreement with the exception that the bare steel frame in the panel model showed somewhat greater strain hardening than did that in the global model. Next, we performed a pushover analysis of the global model, with the panel elements representing the masonry and concrete included and again compared the force-deformation curves obtained from the panel models. We found that the pushover curve from the global model closely replicated the pushover curve obtained from the panel model. (Fig. 19) represents the pushover curves obtained from a typical panel model and the global models for both the case of the bare steel frame and the full structure including steel, masonry and concrete elements. In both cases, the force-deformation behaviors obtained from the global model capture the behavior of the panel model well, providing confidence that the global model is capable of representing the behavior of the structure properly. We observed similar results for all the panels modeled for the building.

The benchmark analysis presented earlier showed that although the ABAQUS model was able to capture the strength and stiffness of the infill panels with a fair amount of accuracy, post-yield behavior, specifically strength degradation is not captured adequately. To account for the effects of this degradation, we modified the backbone curves obtained from our ABAQUS analyses by forcing the masonry strength to degrade to $20 \%$ of the peak strength as shown in (Fig. 20). Note that we did not include any degradation of the steel frame itself, which is modeled using elastic- plastic properties with $3 \%$ strain hardening.

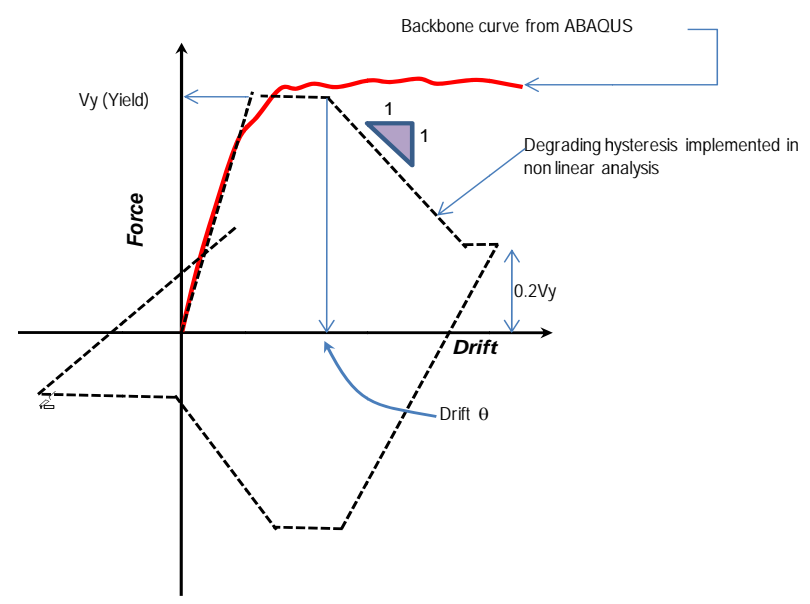

Fig. (20). Degrading hysteresis model for masonry infill implemented in nonlinear analysis.

We observed that the general shape of the backbone curves obtained from our panel models can be classified into two broad categories. In the first panel type, there is a significant permanent strength degradation at drift levels comparable to those anticipated in the building. Since strength degradation initiates at lower deformation levels under cyclic loading than in monotonic loading, we set the point at which strength degradation initiates in our global model at $70 \%$ of the drift indicated by the ABAQUS models. The second panel type does not show any significant strength degradation. For panels illustrating this behavior in our ABAQUS models, we chose the point for initiation of strength degradation as $1.5 \%$, based on an observation of available test data that suggests degradation initiates at this deformation level for typical infill panels.

We modeled the rehabilitated structure by introducing the new structural elements into the existing building model. Specifically, the new shear walls as shown in Fig. (1) were 


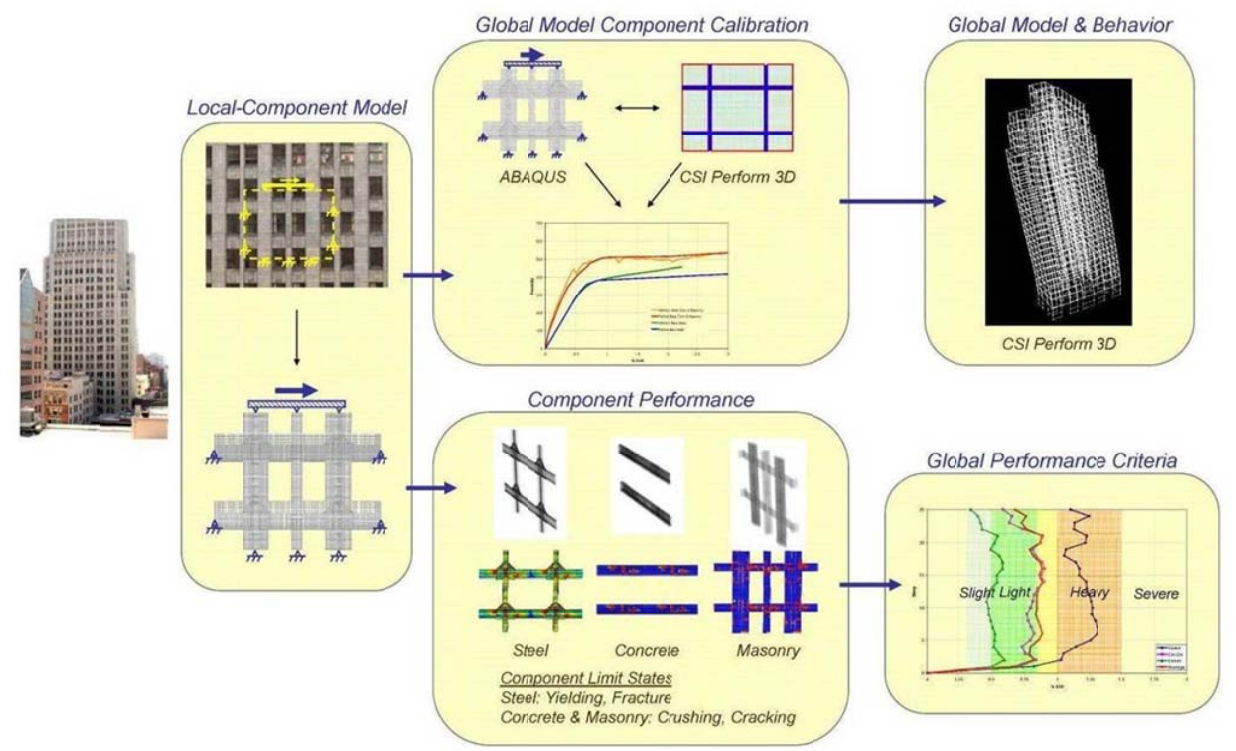

Fig. (21). Figure showing link between ABAQUS micro model and global 3D model.

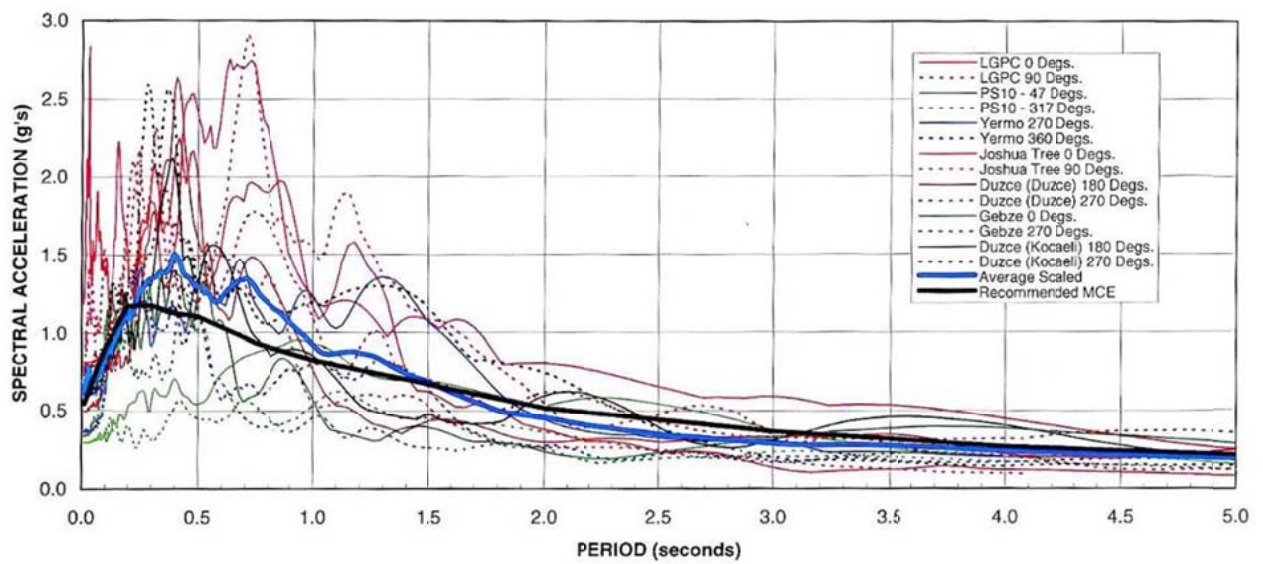

Fig. (22). Scaled MCE SRSS spectra.

modeled with non-linear shear wall elements in Perform 3D. The shear wall decreased the fundamental period of the structure from approximately 3.7 seconds and 3.4 seconds to 2.6 seconds and 1.7 seconds in the $\mathrm{v}$ and $\mathrm{u}$ axis shown in Fig. (3). Since this wall was placed adjacent to main corridor it was perforated with door openings to the units. We specifically modeled the coupling beams to have ACI 318compliant detailing including confined diagonal bars. We set the rotational limit for the coupling beams at $4 \%$ and ensured that $75 \%$ of the mean rotation from the MCE analysis was below this limit. (Fig. 21) shows the isometric view of the global model and explains how the ABAQUS modeling is integrated into the whole analysis.

\section{GROUND MOTION FOR TIME HISTORY ANALYSIS}

We used a suite of 7 ground motions, to perform response history analysis. These ground motions are representative of 84th percentile shaking intensity anticipated at the ground surface for a deterministic characteristic earthquake along the peninsula segment of the San Andreas fault, and having a magnitude approximating 7.9. (Fig. 22) is a plot of the SRSS spectra for the pairs motions, scaled to the MCE response spectrum at ground surface.

\section{SELECTED RESULTS FROM MCE ANALYSIS}

We used the suite of seven ground motions see (Table 1) in the principal direction of the building grouped as strong and weak components and performed a non-linear analysis of the global model. (Fig. 23) shows drift results for the Minna St. elevation for the strong components applied in the north-westerly direction. Drifts comply with the limit for Collapse Prevention which is set at $1.25 \%$ for the typical panel. This also happens to be the drift at which the masonry starts spalling as indicated in the ABAQUS panel model interpreted in conjunction with the benchmark analysis. We have denoted this drift as the onset of heavy damage to provide a qualitative feel to the extent of repair that will be necessary following an earthquake. Other damage limits e.g. moderate, slight and light convey similar message and will 
Table 1. Ground Motions Listed In Order Shown In Fig. (22)

\begin{tabular}{|c|c|c|}
\hline Earthquake & Record & Direction (DEGREES) \\
\hline Denali & Pump Station \#10 & 47 \\
\hline Denali & Pump Station \#10 & 317 \\
\hline Denali & Yermo & 360 \\
\hline Landers & Joshua Tree & 0 \\
\hline Denali & Joshua Tree & 90 \\
\hline Duzce & Duzce & 180 \\
\hline Kocaeli & Gebze & 270 \\
\hline Kocaeli & Duzce & 180 \\
\hline Kocaeli & Duzce & 270 \\
\hline
\end{tabular}

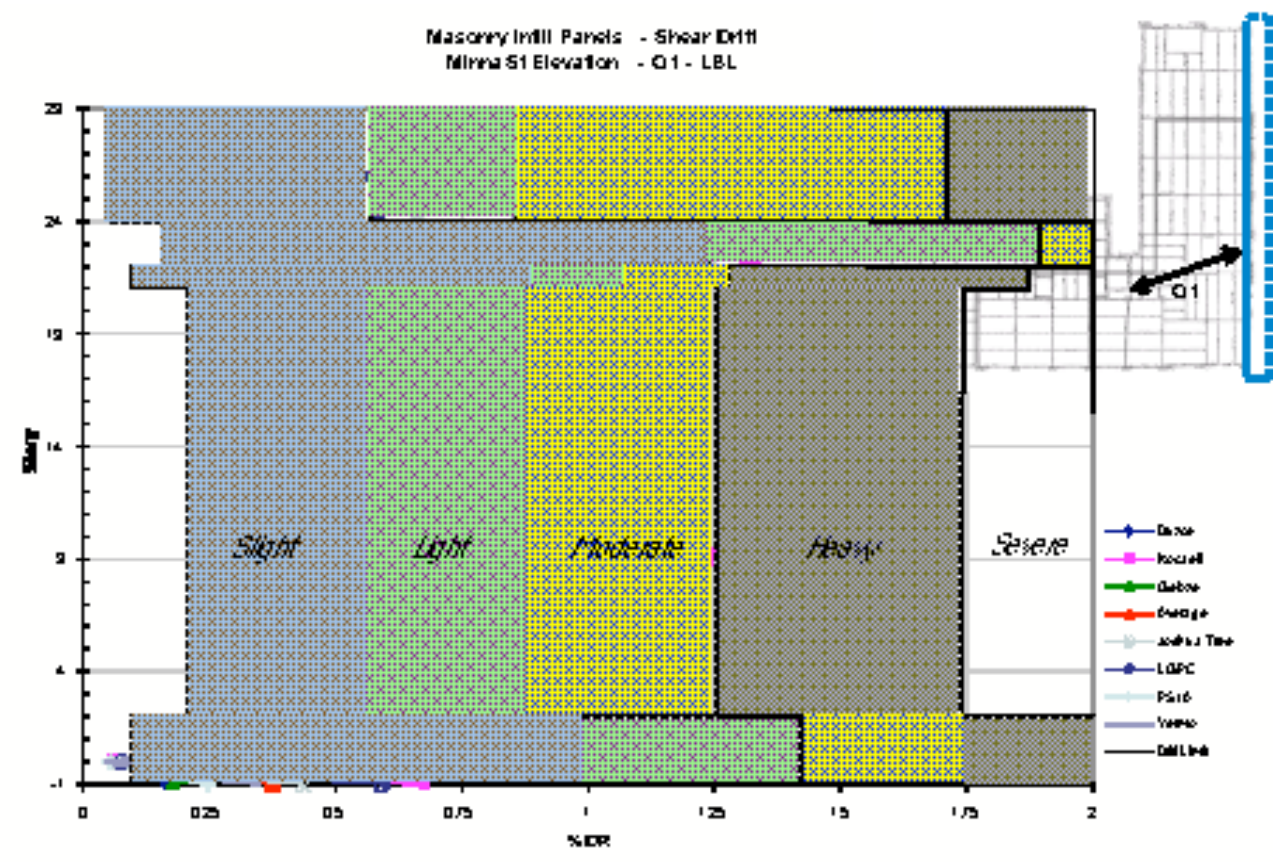

Fig. (23). Infill panel drift along Minna Street.

be appropriate for lesser intensity shaking which is not presented for the sake of brevity.

\section{SUMMARY}

Our analyses of the 138 New Montgomery building demonstrate a practical approach to characterizing the seismic performance capability of steel frames with perforated infill masonry walls. This approach more accurately repre- sents the probable structural behavior of this system than modeling approaches suggested in ASCE-41.06. Further, our detailed modeling approach, together with our benchmark comparison to a laboratory test provided us with good confidence that we could predict likely levels of damage at different levels of earthquake demand.

High fidelity modeling of structural elements, such as illustrated in this paper are being used by engineers with 
increasing frequency when using performance-based approaches to design, evaluate and retrofit buildings. In our opinion, our benchmark study in which we compared our predictive models against a laboratory test was essential to developing sufficient confidence in our approach. We recommend similar benchmarking studies as part of any project that uses analytical techniques to predict the behavior of complex structural elements.

Our implementation of this design approach was costly and time-consuming. Ultimately, seismic upgrades for the structure are estimated to have a construction cost of $\$ 279$ US per square meter ( $\$ 26$ US per square foot) which is considered quite economical for structures of this size. Our approach enabled the structure to retain its historic character and when retrofitted, this building will provide reliable service for many years to come, demonstrating the true concept of sustainability.

\section{CONFLICT OF INTEREST}

The authors confirm that this article content has no conflicts of interest.

\section{ACKNOWLEDGEMENT}

Declared none.

\section{REFERENCES}

[1] "City and County of San Francisco, Building Code" 2007 ed. American Legal Publishing Corporation, 432 Walnut Street, Cincinnati, Ohio 45202-3909 USA.

[2] "ASCE Standard 41-06, Seismic Rehabilitation of Existing Buildings", American Society for Civil Engineers, 2007.
[3] Building Seismic Safety Council, "NEHRP recommended provisions for the seismic regulation of buildings and other structures", FEMA 406, Federal Emergency Management Agency, Washington D.C. 2003.

[4] Applied Technology Council, "Methodology for Development of Structural System Seismic Performance Factors", FEMA P695, Federal Emergency Management Agency, 2009.

[5] ABAQUS, Dassault Systèmes, 10 Rue Marcel Dassault, 78140 Vélizy-Villacoublay, France.

[6] CSI Perform, Computers \& Structures, Inc., 1995 University Avenue, Suite 540, Berkeley, California 94704 USA.

[7] H.B. Kaushik, D.C. Rai, and D.C. Jain, "Uniaxial compressive stress strain model for clay brick masonry", Curr. Sci., vol. 92, no. 4, pp. 497-501, 2007.

[8] R.G. Drysdale, and A.A. Hamid, "Tensile strength of brick masonry", Proc. Int. J. Masonry Constr., vol. 2, no. 4, pp. 172-177, 1982.

[9] A.A. Zarghamee, and K.L. Fok, "Analysis of prestressed concrete pipe under combined loads", J. Struct. Eng. ASCE, Reston, Virginia, vol. 116, no. 7, pp. 2022-2039, 1990.

[10] "ACI 318-08, Building Code Requirements for structural Concrete (ACI 318-08) and Commentary", American Concrete Institute: Farmington Hills, Michigan 48331 USA.

[11] A.A. Elwi, and D.W. Murray, "A 3D hypoelastic concrete constitutive relationship", J. Eng. Mech. Div., ASCE, vol. 105, no. 4, pp. 623-641, 1979.

[12] Z.P. Bazant, and H.O. Byung, "Deformation of progressively cracking reinforced concrete beams" ACI J., vol. 81, pp. 268-278, 1984.

[13] S.P. Schneider, B.R. Zagers, and D.P. Abrams, "Lateral strength of steel frames with masonry infills having large openings", J. Struct. Eng. ASCE, vol. 124, no. 8, pp. 896-904, 1998.

[14] S.P. Schneider, D.P. Abrams, and S.J. Favieri, "Lateral Force Behavior of Brick Infills with Steel Frames", Proceedings of Seventh North American Masonry Conference, University of Noter Dame, June 2-5, South Bend, Indiana, 1996.

(C) Dutta et al.; Licensee Bentham Open.

This is an open access article licensed under the terms of the Creative Commons Attribution Non-Commercial License (http://creativecommons.org/licenses/by-nc/3.0/) which permits unrestricted, non-commercial use, distribution and reproduction in any medium, provided the work is properly cited. 